\title{
BILATERAL OSTEOCHONDRITIS DISSECANS OF THE KNEE IN A BASKETBALL PLAYER: CASE REPORT
}

Jorge Sayum Filho', Emerson Garms ${ }^{1}$, Jorge Sayum², Rogério Teixeira de Carvalho', Marcelo Mitsura Matsuda', Alexandre Nicolini' Benno Ejnisman', Moisés Cohen ${ }^{3}$

\section{ABSTRACT}

The authors report a case of bilateral osteochondritis dissecans in a 17-year-old basketball player who was diagnosed and treated as shown in the literature.

Keywords - Osteochondritis Dissecans; Knee; Sports; Basketball

\section{INTRODUCTION}

Osteochondritis dissecans is a rare acquired condition that affects the subchondral bone and is manifested as a pathological spectrum. Its etiology is unknown. Thus, we present a case that affected a basketball player.

\section{CASE REPORT}

The patient was a 17-year-old white male who was an amateur basketball player. He came to the knee outpatient clinic of the Sports Traumatology Center (CETE) of the Department of Orthopedics and Traumatology (DOT), Federal University of São Paulo (UNIFESP) with a complaint of pain in both knees for around one month.

The pain began insidiously in both knees, without any history of trauma. It improved with non-steroidal antiinflammatory drugs and worsened after exercise practice.

On physical examination, he presented pain in the anterior part of both knees, edema $+/ 4+$ and crepitation. He reported pain on palpation of the medial condyle and was bilaterally positive for Wilson's sign.
The patient underwent AP, lateral and tunnel view radiographs, and two lesions were observed on the lateral part of the femoral condyle, bilaterally. Bilateral magnetic resonance imaging (MRI) was requested, which revealed an osteochondral fragment of approximately $2.5 \times 2.0 \mathrm{~cm}$ in both knees (Figure 1). According to the MRI classification for osteochondritis, the lesions were classified as stage V.

The patient underwent bilateral arthroscopic surgery. The fragments were viewed arthroscopically and were surgically prepared, along with their respective beds, and were fixed using two Herbert screws. The osteosynthesis was verified using intraoperative radioscopy. The two knees underwent surgery in the same operation: firstly the left knee and then the right knee.

The patient was discharge from hospital one day after the surgery, without immobilization, and the stitches were removed 14 days later. Physiotherapy started on the third postoperative day, but no weight-bearing was allowed for six weeks, after which it was progressively introduced. Sixteen weeks after the operation, the patient started to return to sport (Figure 2).

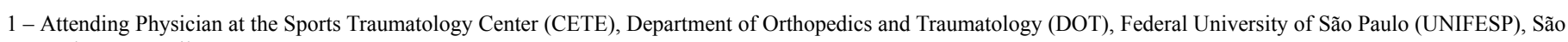
Paulo, SP, Brazil.

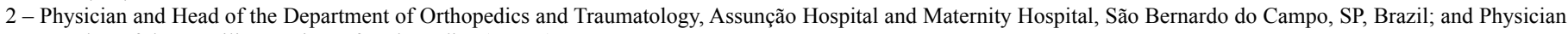
Member of the Brazilian Society of Orthopedics (SBOT).

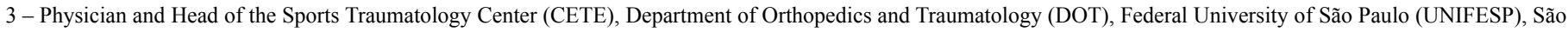
Paulo, SP, Brazil.

Work performed at the Sports Traumatology Center (CETE), Department of Orthopedics and Traumatology (DOT), Federal University of São Paulo (UNIFESP).

Correspondence: Rua França Pinto 186, ap. 61, Vila Mariana, 04016-001 São Paulo, SP. E-mail: jorgesayumfilho@hotmail.com

Work received for publication: October 6, 2010; accepted for publication: December 23, 2010

The authors declare that there was no conflict of interest in conducting this work 


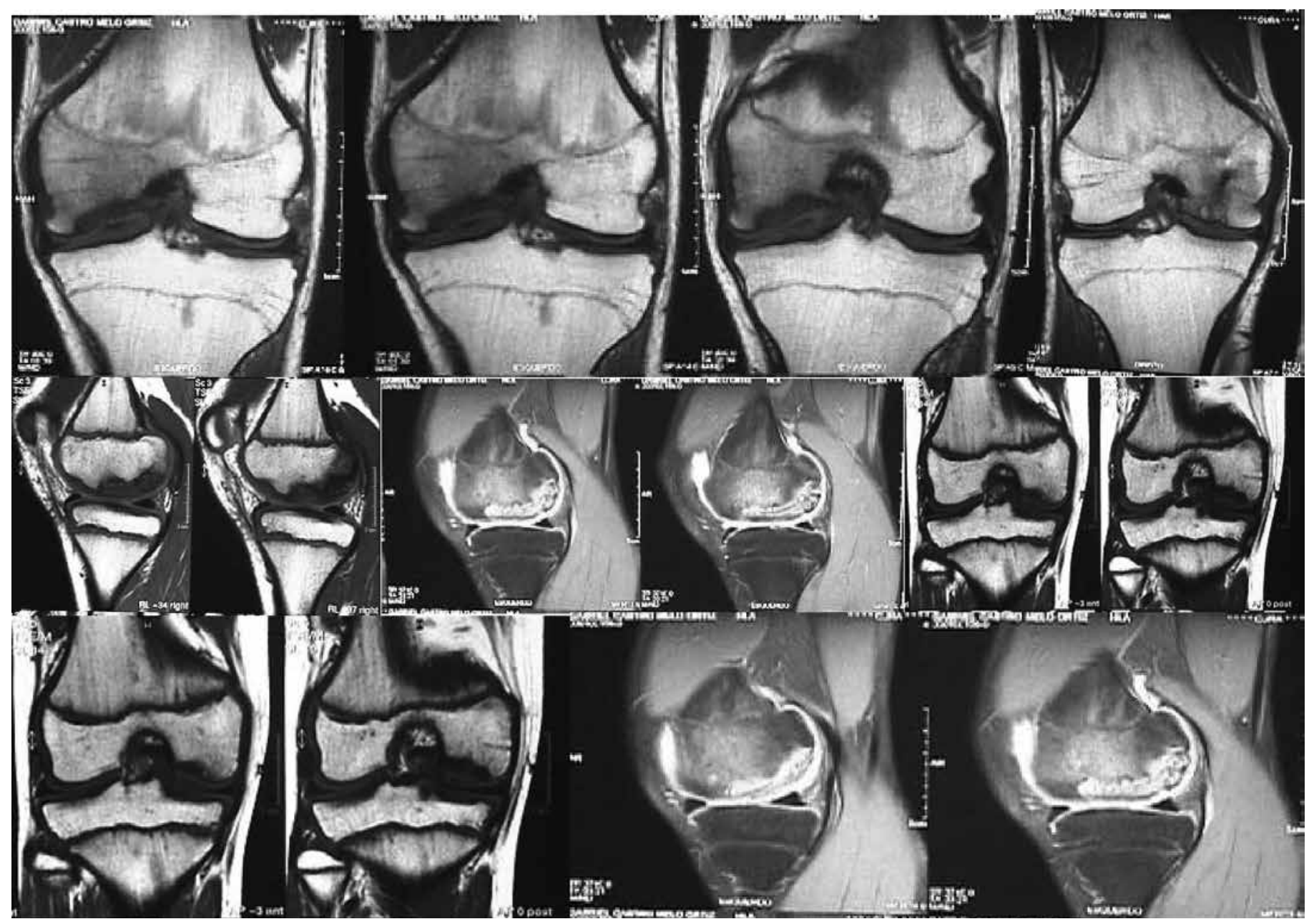

Figure 1 - Preoperative magnetic resonance imaging.

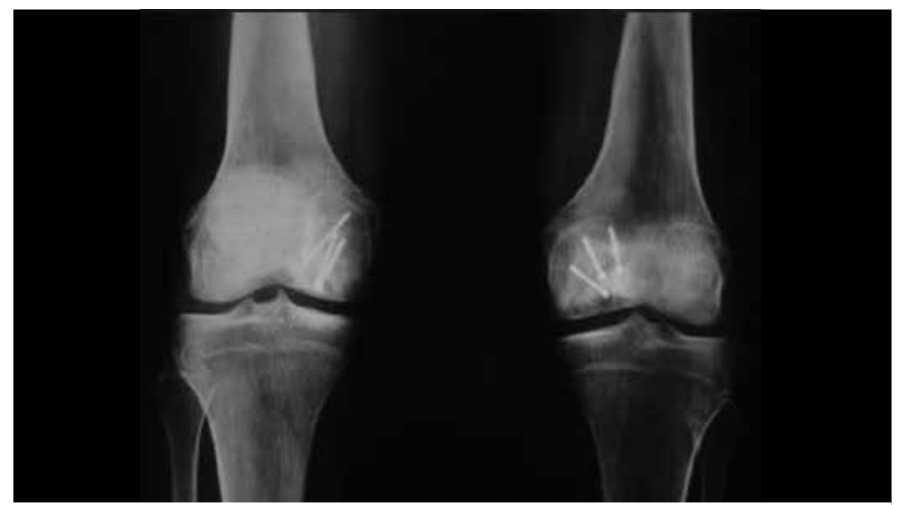

\section{DISCUSSION}

Osteochondritis dissecans (OCD) is an acquired condition that affects the subchondral bone and is manifested as a pathological spectrum ${ }^{(1)}$. It starts with softening of the cartilage, and this may progress to cleavage, partial separation and eventually there may be total osteochondral separation with formation of free bodies ${ }^{(1)}$. The etiology of OCD is unknown, but repetitive microtrauma is frequently reported.

OCD is subdivided into juvenile and adult forms. It is classified based on its anatomical location, surgical appearance, scintigraphic findings, MRI findings and patient age. The juvenile form has a better prognosis that the adult form ${ }^{(2,3)}$.

The clinical presentation of this pathological condition is nonspecific. Since the majority of patients present a stable lesion, pain in the anterior part of the knee, correlated with physical activity, is the main complaint. Patients may or may not comFigure 2 - Postoperative radiographs. plain about instability and they may present antalgic 
gait $^{(4)}$. With palpation, there is generally an area of more intense pain in the lateral part of the distal medial femoral condyle. Wilson's sign may or may not be present. Patients generally present edema and crepitation in the knee ${ }^{(5)}$.

Imaging studies have the aim of characterizing the lesion, monitoring its healing and determining the prognosis for conservative treatment ${ }^{(6)}$. Regarding radiographic evaluations, the tunnel view has particular importance because OCD lesions are typically located in the lateral portion of the distal medial femoral condyle. MRI is useful for determining the size of the lesion, status of the cartilage and viability of the subchondral bone. Scintigraphy may provide information about the biological capacity for the lesion to heal.
In relation to treatment, it has to be borne in mind that conservative treatment is preferred for skeletally immature patients, while surgical treatment should be considered for patients with unstable lesions or for cases in which conservative treatment is unsuccessful ${ }^{(1-4)}$.

Operative treatment includes a variety of techniques, such as: arthroscopic drilling, mosaicplasty, arthroplasty through abrasion, microfracturing, osteochondral grafts, autologous implantation of chondrocytes and fixation of fragments (using cannulated Herbert screws, Kirschner wires and bone pegs, among others $)^{(7)}$.

In the light of all the above points, we reported a case of OCD in a basketball player who was diagnosed and treated in accordance with the literature ${ }^{(1-4)}$.

\section{REFERENCES}

1. Ganley TJ, Flynn JM. Osteochondritis dissecans. In: Scott WN, editors. Surgery of the knee. 4th ed. New York: Churchill Livingstone; 2006. p. 1234-41.

2. Aglietti P, Buzzi R, Bassi PB, Fioriti M. Arthroscopic drilling in juvenile osteochondritis dissecans of the medial femoral condyle. Arthroscopy. 1994;10(3):286-91

3. Aichroth P. Osteochondritis dissecans of the knee. A clinical survey. J Bone Joint Surg Br. 1971;53(3):440-7.

4. Koch S, Kampen WU, Laprell H. Cartilage and bone morphology in osteochon- dritis dissecans. Knee Surg Sports Traumatol Arthrosc. 1997;5(1):42-5.

5. Mubarak SJ, Carroll NC. Familial osteochondritis dissecans of the knee. Clin Orthop Relat Res. 1979;(140):131-6.

6. Bohndorf K. Osteochondritis (osteochondrosis) dissecans: a review and new MRI classification. Eur Radiol. 1998;8(1):103-12.

7. Cahill BR. Osteochondritis Dissecans of the Knee: Treatment of Juvenile and Adult Forms. J Am Acad Orthop Surg. 1995;3(4):237-47. 